\title{
IDENTIFIKASI SPOT DIVING SEBAGAI OLAHRAGA REKREASI DI KAWASAN MANDEH
}

\author{
Ricky Nanda Pratama ${ }^{1}$, Anton Komaini², Andri Gemaini ${ }^{3}$, \\ Alimuddin 4 \\ Jurusan Kesehatan dan Rekreasi, Universitas Negeri Padang, \\ Padang, Indonesia \\ rickynandapratama9@gmail.com
}

\begin{abstract}
The problem in this research is that there is no related information regarding the identification and mapping of diving spots in the Mandeh area. This study aims to identify and map diving spots as a recreational sport in the Mandeh area.

This type of research is descriptive, which aims to describe and map the Diving Spot as a recreational sport in the Mandeh area. Data analysis techniques in this study are data collection, data reduction, data display / data presentation, and drawing conclusions and then verification. Data collection techniques in this study were observation, interview, and documentation.

The results revealed that based on the results obtained, it can be concluded that the Mandeh area has several beautiful diving spots and has historical value. This is evidenced by the results of research where researchers found five diving spots in the Mandeh area, namely Boelongan which is famous for its history, namely MV Boelongan Nederlan which sank in 1942, then Batu Buayo which is identified with its beautiful and unique coral reefs, the Montipora Aquituberculata type, namely coral which is thin and resembles a barrel or funnel, next is Marak Agate where there are turtles and sea anemones, then Marak Labuan which has coral type Coral Foliose, which is the type of growth such as leaves and fungi, then Pagang Dermaga there is planting coral species Acropora Digitata with speda media and accompanied by a school of Scooling Fish, all of which are for recreational sports.
\end{abstract}

Keywords: Diving Spot, Sport Recreation

\section{Abstrak}

Masalah dalam penelitian ini adalah belum ada informasi terkait mengenai pengidentifikasian dan pemetaan spot diving di kawasan mandeh. Penelitian ini bertujuan untuk mengetahui dan memetakan spot diving sebagai olahraga rekreasi di kawasan mandeh.

Jenis penelitian ini adalah deskriptif, yang bertujuan untuk mendeskripsikan dan memetakan Spot Diving Sebagai Olahraga Rekreasi di Kawasan Mandeh. Teknik analisi data dalam penelitian ini yaitu pengumpulan data, reduksi data, display data/penyajian data, dan mengambil kesimpulan lalu diverifikasi. Teknik pengumpulan data dalam penelitian ini adalah Observasi, Wawancara, dan Dokumentasi. 
Hasil penelitian mengungkapkan bahwa berdasarkan hasil penelitian yang diperoleh, maka dapat disimpulkan bahwa Kawasan Mandeh memiliki beberapa spot diving yang indah dan memiliki nilai sejarah. Ini dibuktikan dari hasil penelitian yang mana peneliti menemukan lima spot diving di Kawasan Mandeh yaitu Boelongan yang terkenal dengan sejarahnya yaitu MV Boelongan Nederlan yang karam pada tahun 1942, selanjutnya yaitu Batu Buayo yang di identic dengan terumbu karangnya yang indah dan unik berjenis Montipora Aquituberculata yaitu karang yang tipis dan menyerupai tong atau corong, selanjutnya yaitu Marak Batu Akik yang mana terdepat kura-kura dan anemone laut, selanjutnya yaitu Marak Labuan yang memiliki karang jenis Coral Foliose yaitu tipe pertumbuhannya seperti daun dan jamur, selanjutnya Pagang Dermaga disana terdapat penanaman bibit karang jenis Acropora Digitata dengan media speda dan ditemani dengan gerombolan ikan jenis Scooling Fish yang mana semua spot ini bertujuan untuk olahraga rekreasi..

Kata kunci: Spot Diving, Olahraga Rekreasi

\section{Pendahuluan}

Olahraga merupakan suatu kebutuhan yang sangat penting bagi tubuh manusia, olahraga dianggap penting bagi kebutuhan karena manusia adalah makhluk yang bergerak. Manusia dalam melakukan aktivitasnya tidak terlepas dari proses gerak, sebab tidak ada kehidupan tanpa adanya gerakan. Dan olahraga merupakan aktivitas kebutuhan manusia karena dengan tingkah laku atau aktivitas olahraga secara baik, teratur, terukur dan terarah maka akan menjadikan jiwa dan raga manusia lebih baik, terutama dalam olahraga rekreasi UU RI No.3 tahun 2005 tentang Sistem Keolahragaan Nasional Pasal 17 :" Olahraga Rekreasi, di lakukan sebagai bagian proses pemulihan kembali kesehatan dan kebugaran yang dapat dilaksanakan oleh setiap orang, satuan pendidikan, lembaga, perkumpulan atau organisasi olahraga. Olahraga rekreasi bertujuan: memperoleh kesehatan, kebugaran jasmani, dan kegembiraan, membangun hubungan social atau melestarikan dan meningkatkan kekayaan budaya daerah dan nasional. Salah satu jenis olahraga rekreasi adalah olahraga selam atau diving. Diving atau di sebut dengan olahraga selam yaitu suatu aktivitas fisik manusia yang di lakukan di dalam permukaan air dengan atau tanpa menggunakan peralatan, untuk mencapai suatu tujuan tertentu.

Di Sumatera Barat, khusus nya di kawasan Mandeh, Kecamatan Koto XI Tarusan, Kabupaten Pesisir Selatan ini di juluki "The Paradise of the South"surga dari selatan, mirip Raja Ampat di Papua karena di kelilingi oleh pulau-pulau, Kawasan Mandeh memiliki segudang destinasi wisata alam 
yang bagus untuk di kunjungi. Selain pantai dan gugusan pulau-pulau serta pasir yang putih, kawasan mandeh juga berpotensi memiliki Spot Diving yang menarik dan terkenal dengan pemandangan bawah laut yang indah dengan ombak laut yang cukup tenang untuk kegiatan diving sebagai olahraga rekreasi, namun sayang sampai saat ini belum ada informasi terkait mengenai pengidentifikasian dan pemetaan spot diving di kawasan mandeh sehingga para wisatawan atau pengunjung yang ingin melakukan olahraga diving di Kawasan Mandeh kebingungan dalam mencari dan menemukan spot diving. Berkembangnya sektor pariwisata otomatis akan menggerakan roda usaha yang terkait di dalamnya sehingga menciptakan efek ekonomi multi ganda. Pertumbuhan pariwisata diharapkan akan mengakibatkan pertumbuhan lapangan kerja, pertumbuhan ekonomi, dan bermanfaat bagi masyarakat miskin (Andria, 2018). Dari latar belakang yang telah dipaparkan diatas, maka peneliti mengambil judul identifikasi spot diving sebagai olahraga rekreasi di Kawasan Mandeh.

\section{Metode}

Penelitian ini merupakan jenis penelitian deskriptif, yang bertujuan untuk mendeskripsikan dan memetakan Spot Diving Sebagai Olahraga Rekreasi di Kawasan Mandeh. Hal ini sesuai dengan pendapat Arikunto (2010:3) mengungkapkan bahwa: "Penelitian deskriptif adalah penelitian yang tidak termasuk untuk menguji hipotesis tertentu, tetapi hanya menggambarkan apa adanya suatu variabel, gejala dan keadaan". Berdasarkan kutipan pemikiran tersebut dapat disimpulkan bahwa penelitian deskriptif adalah suatu bentuk penelitian yang digunakan unuk melihat, mengetahui dan mengungkapkan data ataupun keadaan sebagaimana adanya sesuai hasil temuan di lapangan. 


\section{Hasil Penelitian}

\section{Deskripsi Lokasi Spot Diving di Kawasan Mandeh}

a. Boelongan (MV Boelongan Nederland)

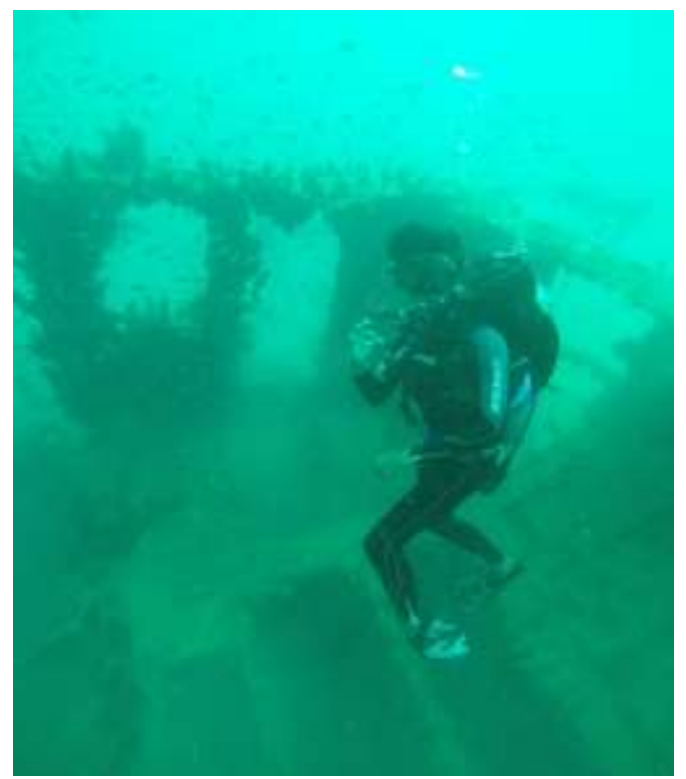

Titik Koordinat:S 01.12'03.59"

$$
\text { E 100.25'30.01" }
$$

b. Pulau Batu Buayo

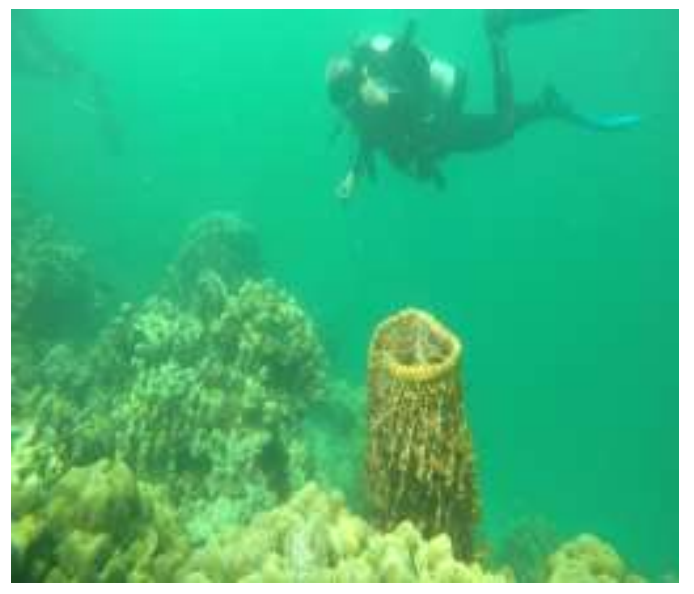

Titik Koordinat:S 01.12'15.80"

$$
\text { E 100.24'01.04" }
$$


E-ISSN2655-2515

P-ISSN2655-1802

c. Pulau Marak Batu Akik

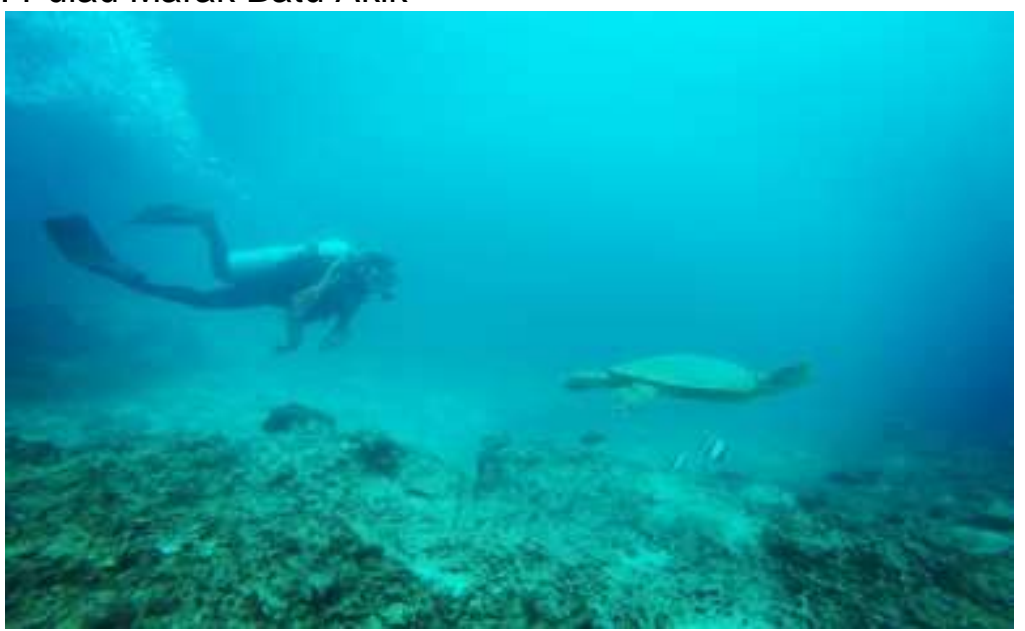

Titik Koordinat:S 01.11'24.10"

E 100.19'56.93"

d. Pulau Marak Labuan

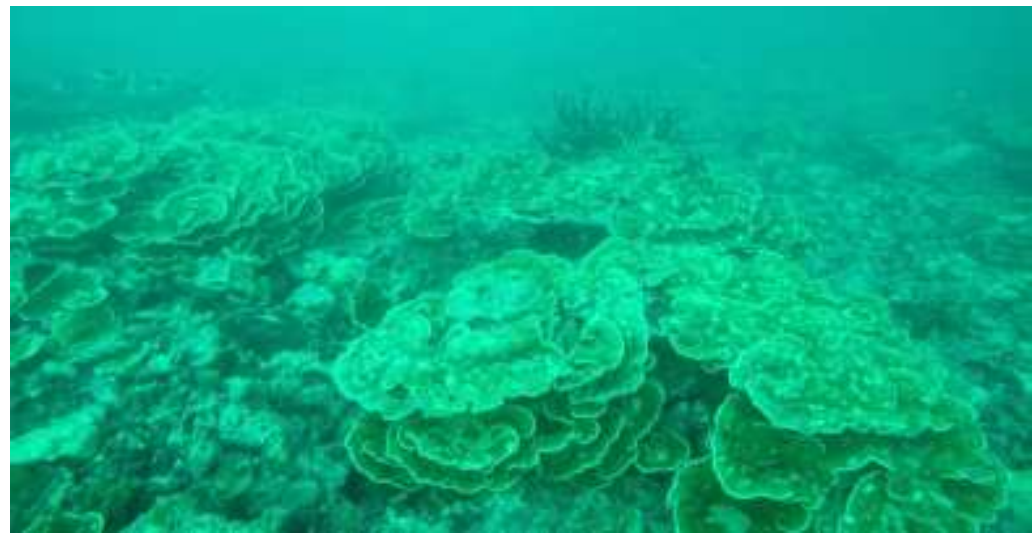

Titik Koordinat:S 01.11'26.13"

E 100.20'18.82" 
E-ISSN2655-2515

P-ISSN2655-1802

e. Pulau Pagang Dermaga

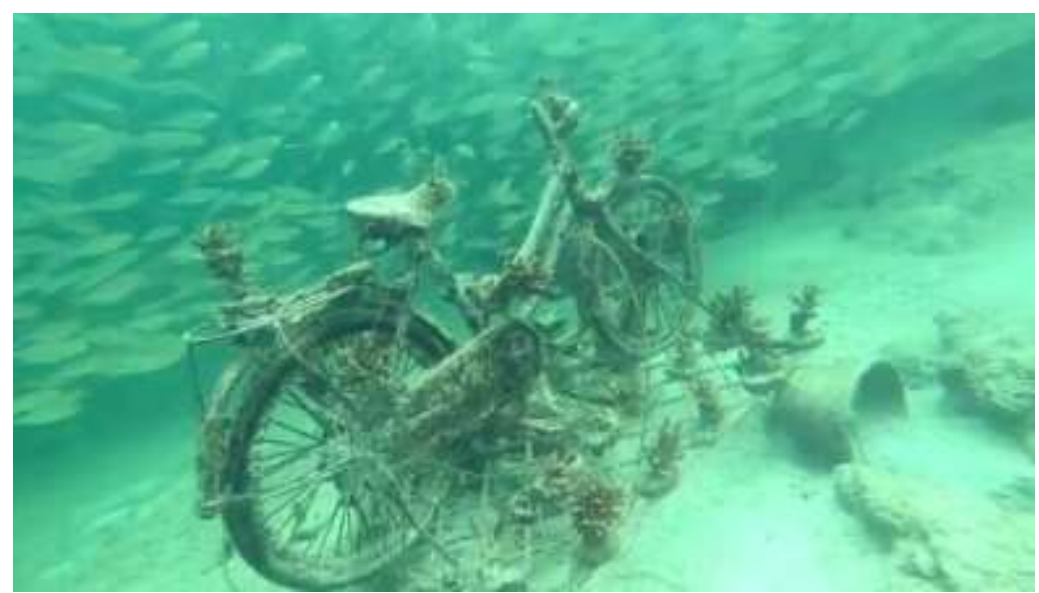

Titik Koordinat:S 01.09’31.38

E $100.21^{\prime} 06.23$ 


\section{Pemetaan Spot Diving di Kawasan Mandeh}

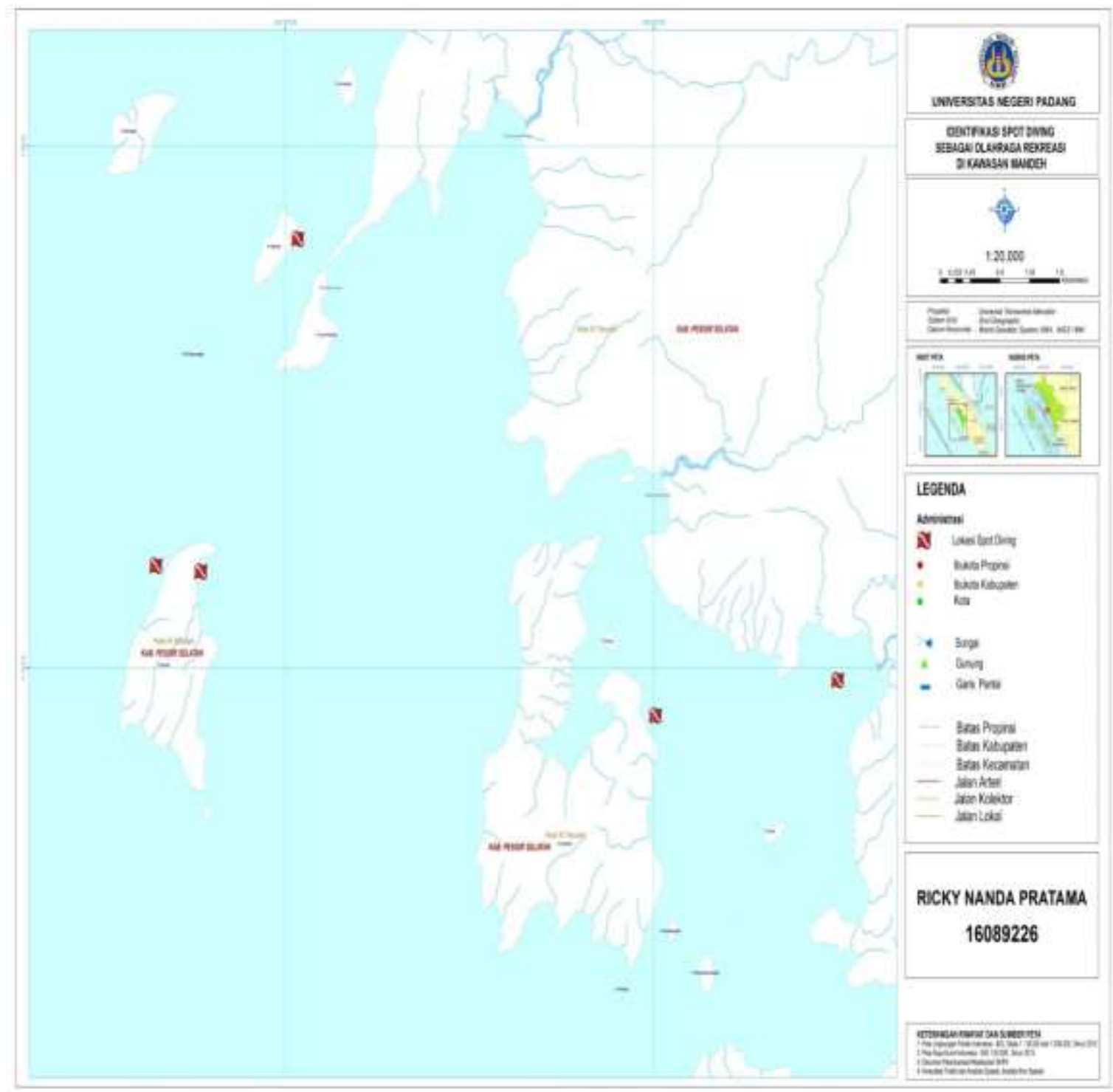

\section{Pembahasan}

1. MV Boelongan Nederland

Spot Boelongan yang peneliti dapatkan memiliki kedalaman 18-29 Meter dibawah permukaan laut, spot ini masuk dalam kategori penyelaman sedang, penyelaman sedang yaitu penyelaman dengan kedalaman 10-30 meter, pada spot ini kita akan mengenang sejarah dimana bangkai kapal MV Boelongan Nederland ini merupakan kapal kargo Belanda yang karam di perairan Teluk Mandeh setelah dibombardir oleh tentara Jepang pada 
tahun 1942. Kapal tersebut dibuat pada tahun 1915 dengan berat 1.052 ton, berukuran panjang $72,6 \mathrm{~m}$ dan tinggi $8 \mathrm{~m}$, lebar badan kapal pada bagian tengah $11,63 \mathrm{~m}$, haluan $10 \mathrm{~m}$, buritan $13 \mathrm{~m}$ dan memiliki dimensi $100 \times 11 \times 3,7$ meter, dengan kekuatan 750 bhp serta kecepatan mencapai 8,25knots.

\section{Spot di Pulau Batu Buayo}

Spot di Pulau Batu Buayo yang peneliti dapatkan memiliki kedalaman 5-9 meter dibawah permukaan laut, spot ini masuk dalam kategori penyelaman dangkal, penyelaman dangkal yaitu penyelaman dengan kedalaman maksimum 10 meter, bagi yang ingin melakukan olahraga selam rekreasi di spot ini tidak harus memiliki sertifikat penyelaman, akan tetapi harus menguasai dasar penyelaman dan harus di damping oleh penyelam professional, jarak pandang atau visibility pada spot ini yaitu di atas 20 meter dan masuk dalam kategori baik, pada spot ini kita banyak menemukan berbagai jenis ikan dan terumbu karang, salah satu icon di spot Pulau Batu Buayo ini adalah adanya terumbu karang yang unik seperti tong dan di huni oleh hewan-hewan kecil didalamnya.

\section{Spot di Pulau Marak Batu Akik}

Spot di Pulau Marak Batu Akik yang peneliti temukan memiliki kedalaman 810 meter dibwah permukaan laut, spot ini masuk dalam kategori penyelaman dangkal, penyelaman dangkal yaitu penyelaman dengan kedalaman maksimum 10 meter, bagi yang ingin melakukan olahraga selam rekreasi di spot ini harus menguasai teknik dasar penyelaman dan di damping oleh penyelam professional, jarak pandang atau visibility dalam spot ini yaitu masuk dalam kategori sedang yaitu 8-20 meter tergantung cuaca karena spot ini berada di ujung kawasan mandeh dan mengarah ke lautan lepas, pada spot ini peneliti hanya menemukan beberapa jenis ikan,anemone dan penyu, di karenakan terumbu karang di spot ini banyak yang hancur sehingga kurangnya populasi jenis ikan di spot ini, bagi penyelam yang ingin melakukan kegiatan penyelaman di spot ini peneliti sarankan waktu yang tepat adalah pagi sampai siang hari, karena di sore hari arus dan ombak di spot ini cukup kuat karena berhadapan langsung 
E-ISSN2655-2515

P-ISSN2655-1802

dengan lautan lepas.

\section{Spot di Pulau Marak Labuan}

Spot di Pulau Marak Labuan yang peneliti temukan berada di kedalaman 11-13 meter dibawah permukaan laut, spot ini masuk dalam kategori penyelaman sedang, penyelaman sedang yaitu penyelaman dengan kedalaman10-30 meter, bagi yang ingin melakukan olahraga selam rekreasi di spot ini harus menguasai teknik dasar penyelaman dan didampingi oleh penyelam professional, jarak pandang atau visibility dalam spot ini masuk dalam kategori sedang yaitu 8-20 meter tergantung cuaca pada saat penyelaman karena spot ini berada di ujung kawasan mandeh yang berhadapan langsung dengan lautan luas, pada spot ini peneliti hanya menemukan variasi ikan-ikan kecil dan terumbu karang sejenis yang lumayan luas, kurangnya jenis terumbu karang yang hidup di spot ini mengakibatkan habitat variasi ikan tidak beragam, dikarenakan banyak karang yang mati, bagi penyelam yang ingin melakukan kegiatan penyelaman di spot ini peneliti sarankan waktu yang tepat adalah pagi sampai siang hari, karena di sore hari arus dan ombak di spot ini cukup kuat karena berhadapan langsung dengan lautan lepas.

\section{Spot di Pulau Pagang Dermaga}

Spot di Pulau Pagang Dermaga ini berada dikedalaman 9-10 meter dibawah permukaan laut, spot ini masuk dalam kategori penyelaman dangkal, penyelaman dangkal yaitu penyelaman dengan kedalaman maksimum 10 meter, bagi penyelam yang ingin melakukan olahraga selam rekreasi di spot ini harus menguasai teknik dasar penyelaman dan di damping oleh penyelam professional, jarak pandang atau visibility dalam spot ini masuk dalam kategori sedang yaitu 8-20 meter, pada spot ini peneliti menemukan banyak variasi jenis ikan dan terumbu karang yang terjaga keasliannya dan di tambah lagi dengan penanaman bibit terumbu karang baru dengan media sepeda dan banyaknya gerombolan ikan Scoolling Fish, hal unik ini akan menjadi kesan yang lebih bagus untuk selam rekreasi di spot ini, bagi penyelam yang ingin melakukan olahraga selam rekreasi di spot ini bisa melakukan penyelaman di pagi siang dan 
sore hari, karena arus yang tenang dan jarak pandang yang bagus membuat spot ini bebas di kunjungi setiap waku.

\section{Kesimpulan}

Berdasarkan hasil wawancara dengan informan kunci dan informan pendukung serta didukung dari hasil pengamatan di lapangan dapat ditarik kesimpulan sebagai berikut:

1) Di spot Boelongan kita akan mengenang sejarah kapal karam yaitu kapal MV Boelongan Nederland yang karam pada tahun 1942 dan menjumpai berbagai jenis-jenis biota laut.

2) Di spot Pulau Batu Buayo ada berbagai jenis karang dan ikan-ikan kecil sebagai penghuninya, keunikan di spot ini adalah adanya terumbu karang jenis Acropora Brancing yaitu karang bercabang dan karang unik jenis Montipora Aquituberculata yaitu karang yang tipis dan menyerupai tong atau corong.

3) Di spot Pulau Marak Batu Akik hanya ada beberapa kehidupan antara lain kura-kura dan anemone, karena banyak karang lain yang rusak dan mati.

4) Di spot Pulau Marak Labuan hanya ada satu jenis hamparan terumbu karang jenis Coral Foliose yaitu tipe pertumbuhan seperti daun atau jamur.

5) Di spot Pulau Pagang Dermaga masih terbilang baru di karenakan adanya penanaman bibit karang jenis Acropora Digitata dengan media sepeda dan ditemani dengan gerombolan ikan-ikan jenis Scooling Fish.

6) Semua spot yang peneliti temukan di Kawasan Mandeh bertujuan untuk olahraga rekreasi.

7) Dari hasil penelitian peneliti menemukan lima spot diving yaitu Boelongan, Batu Buayo, Marak Labuan, Marak Batu Akik dan Pagang Dermaga, masing-masing spot memiliki titik koordinat.

8) Dari kelima spot tersebut menghasilkan sebuah peta spot diving di Kawasan Mandeh. 


\section{Saran}

Berdasarkan hasil wawancara dan pengamatan yang telah dilakukan, maka perlu penulis ajukan beberapa saran sebagai berikut:

1) Bagi pemerintah setempat guna untuk mengembangkan olahraga selam sebagai olahraga rekreasi di Kawasan Mandeh.

2) Bagi para penyelam yang ingin melakukan olahraga selam di Kawasan Mandeh agar selalu membawa penyelam professional.

3) Untuk organisasi-organisasi kampus khususnya UNPDC agar ikut serta dalam mensosialisasikan olahraga selam ini agar berkembang di lingkungan kampus dan menimbulkan minat mahasiswa lain dalam melakukan olahraga selam ini.

4) Bagi mahasiswa seluruh Indonesia khususnya mahasiswa dari jurusan Kesehatan dan Rekreasi Fakultas IImu Keolahragaan Universitas Negeri Padang agar tetap berprestasi dan berkreasi dibidang olahraga bertujuan untuk memajukan olahraga di Indonesia.

5) Bagi pihak dosen maupun instansi-instansi yang berkaitan dengan keolahragaan khususnya olahraga selam agar dapat mensosialisasikan olahraga selam ini agar olahraga selam ini dapat dikenal masyarakat baik dari masyarakat daerah, nasional maupun internasional.

\section{Daftar Pustaka}

Andria, Yogi., Komaini, A. 2018. Pelatihan Tenaga Pemandu Fun Diving Dan Tindakan Penyelamatan Pada Aktivitas Olahraga Bahari Dalam Rangka Mendukung Pengembangan Pariwisata Di Kabupaten Pesisir Selatan. Jurnal Stamina. 1 (1), 489-493.

Ariadno, Baroeno dkk. 2003. Buku Petunjuk 1 Star SCUBA DIVER CMAS Indonesia. Jakarta: Dewan Instruktur Selam Indonesia.

Arikunto, Suharsimi. 2010. Prosedur Penelitian. Jakarta: PT Rineka Cipta

Dewan Instruktur Selam Indonesia. 2017. Pendidikan Akademik Penyelaman Peselam Jenjang A1. Jakarta.

Dewan Instruktur Selam Indonesia. 2006. Pendidikan Akademik Penyelaman Peselam Jenjang A1. Jakarta.

Komaini, Anton. 2018. Pengembangan Pariwisata Olahraga (Sport Tourism) di Kawasan Wisata Bahari Mandeh. (diakses tanggal 05 Maret 2020)

Nababan, Melfa. Dkk. 2018. Analisis Pola Pembinaan dan Pengembangan Olahraga Rekreasi di Federasi Olahraga Rekreasi Masyarakat Indonesia Sumatera Utara Tahun 2017. Jurnal Pedagogik Olahraga 
(Volume 04, Nomor 01, Januari-Juni 2018). HIm. 39.

Ogi Kurniansyah, Riky Azharyandi Siswanto. 2018. Perancangan Identitas Visual Kawasan Mandeh Sebagai Objek Wisata Bahari di Provinsi Sumatera Barat. e-Proceeding of Art \& Design (Volume 5, Nomor 1, Maret 2018) Page 189.

Rosmaneli. 2016. Konsep Dasar Pendidikan Rekreasi. Padang: FIK UNP.

Sandi, Dwi K, Kusumastuti, Salma F. 2019. Museum Bawah Air M.V.Boelongan: Sebuah Gagasan Pembaharuan Museum. Jurnal Walennae (Volume. 17, No. 1, Juni 2019) HIm. 2.

Suratmin. 2018. Pengantar Olahraga Rekreasi dan Olahraga Pariwisata. Depok: Raja Wali Pers.

Sugiyono. 2012. Metode Penelitian Pendidikan (Pendekatan Kuantitatif, Kualitatif dan R\&D). Bandung: Alfabeta. 